\section{THE INTERNATIONAL UNION OF GEODESY AND GEOPHYSICS}

\author{
By DR. J. M. STAGG \\ General Secretary
}

$\mathrm{L}$ IKE all large families, the group of scientific unions with the International Council of Scientific Unions as foster mother has a wide range of interests : one of the elder members of the family, the International Union of Geodesy and Geophysics, is itself big enough and broad enough in outlook to find a place for sciences with superficially so little in common as geodesy and hydrology, seismology and oceanography, vulcanology and meteorology, terrestrial magnetism and atmospheric electricity. So the International Union of Geodesy and Geophysics is a real confederation of unions (or associations, as they are called in the Union), each more or less autonomous, having its own president, secretary and bureau, its own statutes and by-laws and its own procedure for dealing with the problems within its domain. In addition, there is a Commission on Continental and Oceanic Structure which has the status of an association, and, more recently formed, a primary Committee on the Social Value of the Earth Sciences to look after the broader economic, social and political implications of the Union's work. Most of the associations have a number of sections or committees specializing in various aspects of their fields of geophysics.

Though all these constituent organisations of the International Union of Geodesy and Geophysics meet at the time of the triennial general assembly of the Union, they also continue their scientific activities for the most part separately, and arrange their own meetings between assemblies as they choose. Little of this has been possible since the general assembly held in Washington in September, 1939 ; and yet, as the recently published report* shows, it is remarkable how quickly the Union has revived and put its house in order ready to renew its wide activities. There is little doubt that much of this quick recovery is due to the energetic and experienced work of the late general secretary, Brigadier H. St. J. L. Winterbotham. Even before the War had properly begun he had taken steps to safeguard the Union's funds and contrived to keep an emergency organisation running until the ond of hostilities, although the president, Dr. la Cour, had died early in the War and contacts with other senior officers were very restricted. Some of the associations, on their side, continued their work in some measure throughout the War, supporting themselves on the annual subscriptions from their own and neighbouring countries.

As a sequel to a meoting of the Executive Committee of the Union, convened shortly after the end of hostilities, an extraordinary assembly was called in 1946 to put the Union on its post-war feet again. That assembly was held in Cambridge in 1946 and was attended by delegates from sixteen of the pre-war total of some thirty member countries. It made important decisions for the future of the Union, not the least being a radical change in the method of subscription by member countries and institutions. As with most other similar Unions, countries adhering

* International Union of Gcodesy and Geophysics. Report for the War Years 1939-45, with the proceedings of the Fxecutive Committee of the Union, Oxford, December 1945, and the Extraordinary Assembly, Cambridge, July 1946 . Published by the Bureau of the Union at Kew Observatory, Richmond. Surrey. to the International Union of Geodesy and Geophysics have paid (or tried to pay) an annual subscription determined by their population. This was manifestly unfair to countries like India and China, and had obvious results. A decision of last year's extraordinary assembly was designed to provide a remedy : in future each member country may itself choose any one of eight categories of membership, the only proviso being that the category selected has to be formally approved by the Union's council, on which every country has one representative. The category of membership determines the annual subscription to be paid, and the voting power in Council or General Assembly in discussions involving finance.

The details of this innovation have been ombodied in new statutes and by-laws which were adopted by the Cambridge assembly and have since been approved by all adhering countries. These new statutes and an account of the other decisions made by the extraordinary assembly are published in the 1946 report: the report also includes brief summaries of the activities of the various associations since the Washington meeting, a list of the officers of the Union and its component organisations, and the text of an agreement recently made between the International Union of Geodesy and Geophysics (as one of the family of the International Council of Scientific Unions) and U.N.E.S.C.O. By this agreement the International Union will play its part in disseminating information on geodetic and geophysical subjects in countries where contacts on eultural and scientific matters have hitherto been few : and in return, U.N.E.S.C.O. will use its good offices to promote these contacts by financial support for publications and meetings. U.N.E.S.C.O. has already allocated grants from its 1947 budget for this purpose.

U.N.E.S.C.O. will also help in another field of the International Union's activity. Real progress in geodetic and geophysical subjects requires the closest possible international collaboration on a long-term basis. Sound theories concerning isostasy, or the figure of the earth, concerning the nature of the internal structure of the earth as revealed by earthquakes, or the form of the earth's magnetic and electrical fields, or, again, concerning ocean currents or the circulation of the atmosphere, cannot be achieved in a year or two. In each of these fields of investigation there is a great need for a central bureau, maintained on a more or less permanent basis, where at least all the main facts can be collected and made available to those specialists, wherever they be, who are capable of studying them. Since its formation in 1919 the International Union of Geodesy and Geophysics has become responsible, sometimes with other interested unions or institutions, for maintaining several such permanent or quasi-permanent services : the International Seismological Summary, the Isostatic Institute in Helsinki, the International Latitude Service, and the Bureau International de l'Heure are examples. The maintenance of these services, with their staffs and publications, has become a continuous drain on the funds of such unions as the International Union of Geodesy and Geophysics, even to the detriment of other investigations which equally require international co-operation though on a shorter term basis. Following on the U.N.E.S.C.O. agreement, it is therefore a good omen for future development in geodetic and geophysical science that U.N.E.S.C.O. will try to allocate grants for these bureaux and so relieve the International Union to 
engage in the many other important problems which await investigation.

With the example set by the parent union at its 1946 assembly, many of the International Union's associations have had meetings of their own executive committees and councils to put their post-war houses in order and to make plans for the next general assembly, which will be held in Oslo during August 19-28, 1948. Partly in anticipation of that assembly and partly to renew and extend interest in the work of the Union, a pamphlet describing its organisation and scientific activities and those of its constituent associations and commissions has just been published by the Union's Bureau (at present at Kew Observatory, Richmond, Surrey), where copies can be obtained.

\section{THE SWEDISH DEEP-SEA EXPEDITION}

\section{BY PROF. HANS PETTERSSON}

$\mathrm{T}$ HE Swedish Deep-Sea Expedition left Göteborg on July 4 on board the 1,400-ton motor-schooner Albatross, which had been specially fitted out for the purpose at the Lindholmen shipyard with airconditioned laboratories and accommodation for the scientific staff, dark rooms, workshops, cold-storage room, electric winches, etc. The main purpose of the cruise, which is expected to last for fifteen months, is to investigate the deep ocean bed and its deposits by means of new methods developed in Sweden during the war years. The first part of the cruise, between Madeira and Panama, has now been completed. Some of the results are here briefly summarized.

A new and powerful echo-sounding equipment has been constructed for the Albatross by the Marine Instruments, Ltd., of London (formerly Henry Hughes and Sons, Ltd.), in order to get detailed and continuous records of the depth down to at least 7,500 metres. The records so far obtained go down to more than 6,000 metres and are very interesting. They prove that older views of the deep-sea bottom as a smooth, perfectly level surface, especially in the depressions, are radically wrong, at least as regards the part of the Atlantic Ocean which has been traversed. Such surfaces extending over several miles of our course were comparatively rare. Instead, the depth curve moves incessantly up or down, generally by gentle undulations but quite often rising or falling by distinct steps, 100 to more than 300 metres high and from less than one nautical mile to a few miles broad. The change in depth is sometimes so abrupt that the recorder cannot follow it, thus indicating nearly perpendicular walls hundreds of metres in height. One gets the impression of fault lines stretching more or less obliquely across the course. In other cases the slope is steadier, rising or falling by as much as 1:10, or even steeper. In certain places where the record tends to become confused, the bottom appears to be covered with small hills or hummocks, the record showing three or more convex lines, partly overlapping or intersecting at one point.

Crossing the central Atlantic Ridge, where the bottom was pronouncedly uneven and rich in steps or hummocks, its highest point found by us, quite close to the place where the Admiralty chart has the depth of 934 fathoms, in lat. $23^{\circ} 10^{\prime} \mathrm{N}$., long. $45^{\circ} 10^{\prime} \mathrm{W}$., has a minimum depth of only 786 fathoms or about 1,440 metres. Evidently a close net of echograms will be required for any detailed study of the morphology of the Atlantic bottom.

In the Caribbean Sea the depth curve along our course from Martinique to Panama was much steadier than in the open Atlantic, hummocks and steps in the curve were rare, and the depth remained constant to within a few fathoms over distances of 50-100 nautical miles or even more. It is interesting to note that bottom features similar to those of the Caribbean were found also between Algiers and the Tyrrhenian Sea by the Swedish Expedition to the Western Mediterranean on board the skagerak in 1946.

This surprising unevenness of the deep Atlantic bottom proved a serious complication in our attempts to measure the thickness of the sediment carpet by the method developed by Prof. W. Weibull of Bofors, who accompanied the Expedition to Panama. By means of depth charges detonating at depths of 500, 2,500 or 4,500 metres below the surface, echoes are set up from the bottom itself as well as from reflecting surfaces deeper down in, or below, the sediment. Hydrophones of special construction suspended from the ship convert the sound-waves into electric impulses which are recorded on an oscillograph. Where the bottom profile is rough, diffuse reflexions obscure the oscillograms, whereas over a smooth bottom 'deep echoes' may be recorded. The values found (uncorrected for the somewhat higher velocity of sound in the sediment than in water) vary in the open Atlantic between 300 and nearly 2,500 metres.

In the Caribbean Sea, with its much smoother bottom, the oscillograms are very clear and give values which increase from east to west, from 250 metres to a maximum of 900 metres. The total depth of the reflecting surface, presumably the rocky floor beneath the sediment carpet, thus varies between 4,800 and 7,800 metres in the Atlantic and between 2,900 and 5,600 metres in the Caribbean Sea. In the western Mediterranean the maximum depth of a reflecting surface found in 1946 right in the centre of the Tyrrhenian. Sea was 2,600 metres at a water depth of 3,600 metres. It will be of interest to continue these measurements also in the central Pacific Ocean, where we intend also to use depth charges exploding in the sediment itself.

Dr. B. Kullenberg, by means of his piston coresampler, has taken some dozen cores from depths between 4,000 and 5,600 metres, most of them 10-15 metres long. Some of those taken in the open Atlantic in depths of 5,000 metres or more consist of red clay, which becomes very compact and takes on a deep chocolate-brown colour in the lower levels. Occasionally layers rich in Foraminifera are found intercalated in the red clay. Assuming the latter sediment to increase in thickness by $8 \mathrm{~mm}$. in 1,000 years in the Atlantic Ocean, the lower strata of a core 15 metres long should have been deposited nearly two million years ago, or before the end of the Tertiary Age, when the deep ocean water is generally assumed to have been considerably warmer than during the Quaternary Age. This would seern to make it difficult to uphold an opinion prevalent among oceanographers, namely, that the limedissolving effect of the ice-cold Antarctic bottom current is the main or only agency capable of converting calcareous ooze into red clay.

In a 15-metre long core taken from a depth of nearly 4,900 metres at the centre of the Caribbean 